\title{
School-based curriculum development in Scotland: Curriculum policy and enactment
}

\author{
Mark Priestley, Sarah Minty and Michelle Eager
}

School of Education, University of Stirling

\begin{abstract}
Recent worldwide trends in curriculum policy have re-emphasised the role of teachers in school-based curriculum development. Scotland's Curriculum for Excellence is typical of these trends, stressing that teachers are agents of change. This paper draws upon empirical data to explore school-based curriculum development in response to Curriculum for Excellence. We focus on two case studies secondary schools within a single Scottish local education authority. In the paper we argue that the nature and extent of innovation in schools is dependent upon teachers being able to make sense of often complex and confusing curriculum policy, including the articulation of a clear vision about what such policy means for education within each school.
\end{abstract}

\section{Key words}

Curriculum; teachers; schools; curriculum development; innovation

\section{Introduction}

In common with many countries, curriculum policy in Scotland has undergone a period of intense change in recent years. Since the publication of A Curriculum for Excellence in 2004 (SEED 2004) by the Curriculum Review Group on behalf of the Scottish Executive, the new Curriculum for Excellence (CFE) has been implemented through a phased process of reform across Scotland, culminating with the mandated implementation of changes in 2010-11. CfE is distinctive in relation to other recent Scottish curricular reform in that it emphasises the role of teachers as 'agents of change' (SEED 2006), thus reaffirming the importance of school-based curriculum development (SBCD) in Scottish schools. As such, Scotland typifies an emerging tendency in curriculum policy in the UK and elsewhere to construct teachers explicitly as professional developers of the curriculum (e.g. Goodson 2003; Priestley et al. 2012; Nieveen 2011). Such developments claim to combine the best features of top-down and bottom-up approaches to curriculum planning and development, providing both central guidance for schools (thus ensuring the maintenance of national standards) and sufficient flexibility for practitioners to take account of local needs. This is a significant shift, at least in terms of policy rhetoric, given several decades of policies that worked to de-professionalise teachers by imposing prescriptive curricula and oppressive regimes of testing and inspection (Smyth and Shacklock 1998; Keddie Mills and Pendergast 2011).

Nevertheless, despite this apparent shift, the implementation of the new curriculum has not been as smooth as hoped for by its architects. Recent research in Scotland (Baumfield et al. 2010; Priestley and Minty 2012a; Priestley, Biesta and Robinson 2012; Priestley, Robinson and Biesta 2012), while 
indicating significant levels of engagement with $\mathrm{CfE}$, depicts an often confused picture, pointing to:

- teacher anxiety about CfE (especially in respect of assessment and the new National Qualifications);

- highly variable approaches to implementation;

- a lack of fit between teachers' implicit theories about knowledge and learning and the new curriculum;

- considerable tensions in policy and practice (particularly between the putative developmental thrust of CfE and a culture of accountability still prevalent in Scottish schools).

These difficulties have been compounded by a lack of clear specification of process in the new curriculum (see Priestley 2010), a lack of time available to teachers to make sense of what are in many ways complex and unfamiliar concepts, and (especially in secondary schools) a paucity of the sorts of collegial, cross-school teacher relationships essential to the development of collaborative professional cultures (Priestley, Biesta and Robinson 2012). The net result in many schools has been superficial, first order changes to systems and paperwork (Cuban 1988), while the established structures, beliefs and practices of schooling remain substantially unchanged.

This should come as no surprise. The difficulties inherent in the translation of central curriculum policy into practice have been well-documented. For example, research has pointed to the inevitability of teacher mediation of policy (Osborn et al. 1997; Cuban 1998; Elmore 2004) - the iterative refraction (Supovitz 2008) that occurs as policy is translated as it migrates from setting to setting - and the fact that teachers often face difficult contradictions in their work as a result of conflicting policy imperatives (Reeves 2008). This often produces what Supovitz and Weinbaum (2008) refer to as the 'implementation gap' between policy intentions and classroom practice. CfE is inevitably subject to such issues, and thus offers an interesting new context for re-examining schoolbased curriculum development, especially given the increasing worldwide popularity of this new curriculum model (Young 2008; Sinnema and Aitken in press).

The research reported in this paper is concerned with teachers' enactment of CfE in a particular Scottish local authority. We examine school-based curriculum development (SBCD) in response to these changes in national curriculum policy. In the paper we explore two contrasting case studies secondary schools that have approached the enactment of the new curriculum in different ways, and with varied methods and results. These schools are part of a wider project examining the implementation of CfE. They have been selected for this paper because their distinctive approaches to engagement with CfE - within very similar contexts - offer considerable insights into the differing effects of these particular approaches to school-based curriculum development. The paper thus explores the internal conditions in the schools - the institutional logics (Young 1998) of SBCD which impact upon the enactment of CfE. The paper first provides a short overview of the national 
and regional context within which both schools have undertaken SBCD, before outlining the empirical research that underpins our conclusions. We then describe the case studies thematically, providing an analysis of the factors that are significant in shaping institutional responses to the new curriculum.

\section{Curriculum innovation in Scotland}

Since 2002, schools in Scotland have been faced with a series of curricular and pedagogical innovations that arguably present new and radical visions of schooling. CfE has been heralded by its architects as 'one of the most ambitious programmes of educational change ever undertaken in Scotland' (Scottish Government 2008, p.8). It is said to build upon earlier programmes of reform, notably Assessment is for Learning (AifL: see, for example, Hayward, Priestley and Young 2004; Hutchinson and Hayward 2005) ${ }^{1}$, which have sought to shift the emphasis in classrooms away from inputs by teachers towards the development of autonomous, self-directed learners. CfE is often claimed to be distinctive, but as we noted in the introduction to this paper, it is typical of much contemporary worldwide curriculum policy, manifesting a set of common trends or features, including the following identified by Michael Young (2009, p.1): 'the introduction of National Qualifications Frameworks; the shift to learning outcomes; and the move from subject specific to generic curriculum criteria'.

CfE has attracted some criticism for its lack of theoretical rigour (Priestley and Humes 2010). According to Priestley and Humes, the curriculum combines features from competing curricular models (see also: Stenhouse 1975; Kelly 1999). It is pertinent to this paper to briefly examine these theoretical issues, as they impact upon the potential of schools to engage with SBCD. CFE was initially framed around a set of purposes, the Four Capacities ${ }^{2}$, which provide a particular starting point for SBCD, based around the development of processes and the specification of content to achieve curricular aims. However, subsequently the curriculum has also been constructed in terms of Experiences and Outcomes ${ }^{3}$, which Priestley and Humes suggest offer an alternative starting point for SBCD, involving an audit approach to curriculum development and arguably encouraging a culture of strategic compliance (Priestley 2010). Interestingly, our case study schools provide examples of both of the above approaches to SBCD.

Within this national policy landscape, the local education authority participating in our research has developed a relatively distinctive model for the enactment of these national policies. A key part of this approach has been an ongoing programme of teacher professional learning (TPL) to foster the development of formative assessment and dialogical pedagogies. Over the course of several years, the authority has run or facilitated pedagogy-specific courses, with an emphasis on improving teachers' understanding of methodological approaches fit for achieving the purposes framed within its Learning, Teaching and Assessment policy. A number of interviewees from our case study schools had participated in one or more of these initiatives. Such activity is relatively common within Scottish education authorities. However, the authority in our study is fairly distinctive in that it has 
gradually moved away from a 'tips for teachers' approach inherent in their earlier teacher development programmes. These tended to focus on the development of pedagogic and formative assessment techniques (for example, traffic-lighting, questioning techniques and feedback through marking), rather than being concerned with broader purposes of education. The subsequent development of a coordinated model and a set of underpinning principles - participation, dialogue, engagement and learning (see Figure 1 below) - has formed the basis of the authority's approach to $T P L$, and has grounded the subsequent development of the Learning, Teaching and Assessment policy. The model is explicitly underpinned by an assumption that learning episodes should epitomise these principles, leading ultimately to the development of the capacity for critical and creative thinking, and for metacognition. Instead of teachers being told to adopt certain techniques such as those listed above (with the attendant risks that these will be adopted uncritically), such techniques were to be seen as tools that were expressly fit for purpose to achieve specific educational goals (see Hayward and Boyd 2009).

Figure 1: the Local Authority's Model for Learning, Teaching and Assessment

It would be misleading to suggest that the above-described initiatives have driven change unproblematically in the authority's schools. Research reported elsewhere, which we briefly summarise here, points to a number of issues. The penetration of the model into schools which participated in the research has been patchy as many teachers have not engaged with its core ideas in a significant sense (for example, see: Priestley and Miller 2012; Priestley and Minty 2012a). Moreover, the schools face a range of common implementation problems that have their roots in the external environment: these include the current situation of financial cuts, confusions emanating from tensions within and between national and authority policies (for example, Minty and Priestley, 2012, document the tensions between CfE and the local authority's comparatively prescriptive Numeracy Policy and Literacy Project) and a strong, national attainment agenda, which has been argued to exert a strong distorting effect on the translation of curricular aims into practice (Cowie et al. 2007). Teachers have to grapple with the complexities, and at times incoherence, of the curricular policy described above.

\section{Research design}

In 2011, we undertook research into teachers' enactment of CfE. This adopted a case study approach, initially drawing interviewees from three types of professional networks within the authority: an associated schools group (ASG - a cluster of a secondary school and its associated primaries); secondary teacher specialist subject networks; and authority development officers. The research also included a survey, conducted online $(n=716)$. The findings, reported elsewhere (see Priestley and Minty 2012a) largely support the conclusions drawn from the qualitative dataset. A total of 43 in-depth semi-structured interviews were conducted with 30 participants, including three headteachers, 14 teachers and four representatives from the local authority. In total, teachers from 
10 schools (two primary and eight secondary) were involved in the research. This paper focuses on data collected in two of the secondary schools.

The research addressed the following research questions:

1. What are stakeholders' understandings of CfE? How does this differ from teachers' existing practices?

2. What changes have emerged as a result of $\mathrm{CfE}$, in relation to whole school practices, school culture and teachers' personal abilities?

3. What factors have enhanced or hindered teachers' implementation of the changes?

4. How do teachers respond to perceived increased levels of professional autonomy and creative freedoms inherent in CfE?

A range of different practitioners participated in the research, including Headteachers, teachers, members of secondary subject and curriculum development networks, and education authority staff. Data were mainly generated through one-to-one, semi-structured interviews. Most respondents were interviewed twice, with an interval of 3-6 months between interviews. This allowed us to gauge progress in curriculum development and changing teachers' views towards the implementation of CfE. Analysis of data comprised an interpretivist, grounded theory methodology (Charmaz 2000; Corbin and Holt 2005). This enabled both a bottom-up, grounded approach to coding - allowing themes to emerge from the data - as well as the application of social theory to subsequently categorise the themes, thus making sense of the complex social systems encountered in schools. Data were initially open-coded to identify themes. This process generated a large number of descriptive themes emerging from the dataset. The themes were then grouped, following discussion by the research team, generating a smaller number of interpretive themes relating, for example, to teachers' curriculum making practices, their understandings of the new curriculum and their confidence in its implementation. For this paper, with its narrower focus on two secondary schools as separate case studies, we subsequently applied the interpretive themes to each case, undertaking a cross-case analysis to identify complementary and contradictory trends. This latter process entailed an analytical separation of structure and culture in each setting, guided by the social theory of Archer (1988 - see Priestley 2011a,b for a fuller description of this approach).

The paper offers a comparison of efforts in two secondary schools to enact the new curriculum. These schools were selected from the wider dataset for the purposes of this paper because of overt differences between them in respect of their approaches to school-based curriculum development. Readers interested in the wider findings of the project should refer to Minty and Priestley (2012) and Priestley and Minty (2012a, b).

- The first secondary was selected from an ASG cluster of associated schools, researched for the project and identified by the Local Authority as being at an early stage of implementing CfE. Data comprised semi-structured interviews with the Headteacher and three volunteer 
teachers (each interviewed twice), and notes from meetings attended by the researcher.

- A separate secondary was subsequently identified within the authority as a putative 'early adopter' of CfE. Data were generated through interviews with the Headteacher and nine teachers (four of whom were interviewed twice), as well as documentation from the school. The participants were all volunteers, drawn from a pool of teachers involved at various stages of the development of a school programme set up to address the school's implementation of CfE.

The data are presented thematically. This allows for the comparison of specific features of each case. The following descriptions focus on teachers' perceptions of the issues impacting upon the enactment of CFE. We acknowledge at the outset that teachers' prior experience, backgrounds and biographies (both personal and professional) impact greatly on their ability to engage with SBCD. However, a detailed discussion of these is beyond the scope of this paper; therefore we do not present in-depth biographical information about the individual interviewees. Instead we focus more narrowly on the contextual issues within each school - the cultural and structural features of each context (Archer 1988) that help shape SBCD. We explore the views of teachers towards the new curriculum, but also unpack contextual (cultural and structural) features of each setting, as these are crucial in framing what is possible in terms of SBCD. We first present a short vignette about each school, followed by a discussion of the perceptions of teachers in relation to SBCD within each context.

In order to protect the anonymity of the schools and individuals involved, the schools are referred to by pseudonyms (Townview High School and Braebank Academy), and the anonymity of the teachers is preserved as far as possible. Interviewees are identified solely by role (e.g. teacher, Headteacher), and all are referred to as female. Given that the focus of this paper is on identifying attitudes towards the new curriculum and approaches to its implementation, rather than on the analysis of change over time in the schools, we have not differentiated between first and second interviews, except in isolated instances where it is necessary to make the distinction (in which case this is mentioned in the text of the article). Quotations reproduced in the paper are illustrative of general trends in the data for each case study, unless marked as otherwise. All data are treated as confidential, being only accessible to the project researchers, and not available to the Local Authority or other third parties. Interviewees maintained the right to withdraw throughout the project. The research complied with the ethical guidelines of the British Educational Research Association.

\section{School context}

\section{Townview High School}

Townview High is the sole secondary school for a medium-sized town and surrounding villages. The school has experienced a period of flux in recent years, with several Headteachers in quick 
succession, and school inspections that have been critical of poor results, indifferent leadership, and the poor physical state of the buildings. This had contributed to the school's reduced standing in the local community and very low staff morale. The most recent inspection report highlighted improvements under the tenure of a new Headteacher, commenting favourably upon on positive developments to school ethos, staff morale and staff teamwork.

Both the current Headteacher and her predecessor (an acting head) have worked to rebuild the school's reputation and improve the physical layout of the school, within the resources available. In an interview, the Head emphasised the need to bring 'attainment back to the forefront' alongside improving morale, improving timekeeping and appearance, supporting staff and 'getting children to enjoy their education'. She has been heavily involved in promoting the school positively in the community and in building a positive relationship with the parent council. The noted improvement in morale was partly attributed by interviewees to turnover of staff. We saw considerable evidence of recent innovation in response to curriculum policy change. This contrasted with the apparently moribund nature of the school in recent years, and included initiatives such as the development of teacher learning communities, peer observation of teaching, a focus on pupil feedback and selfassessment, and work around primary/secondary transition alongside local primary schools. However, it is fair to say that resultant changes in practices were in their early stages at the time of the research.

Morale, while improved under the tenure of the new Headteacher, remained fragile, and indeed we noted a marked decline between the first and second stages of the research (February and June 2011). The Head noted that the threat of redundancies, compulsory transfers and temporary contracts made staff 'very nervous', and made it difficult to 'keep people's momentum [up]'. She attributed low morale directly to staffing instability and to the poor physical state of the buildings. Interviewees raised further concerns around wider issues relating to pay, conditions and teacher pensions, as well as the perceived pressures associated with enacting CfE.

\section{Braebank Academy}

To an extent, Braebank Academy offers a contrasting picture; however there were some similarities with Townhead which are discussed below. One major difference was that Braebank had developed a clear vision of what CfE meant for its programmes, and had made considerable progress in developing a programme which sought to address the purposes and principles of CFE. This was despite considerable baseline similarities between the schools, including a history of indifferent leadership and poor inspection results, followed by the appointment of new Headteachers (although we note that this latter event occurred two years earlier in Braebank, potentially placing it two years ahead of Townview in a cycle of innovation).

Braebank Academy is a small secondary school, serving a small, rural, town and its surrounding villages. An inspection report, undertaken prior to the appointment of the current Headteacher, 
criticised teaching and identified weaknesses in the previous head's leadership (despite this, teacher morale was judged to be good). Two follow-through inspections were undertaken; the second following the appointment of the current head. The report notes the positive impact resulting from changes made to the school's curriculum and timetable. It also refers to the benefits of a new form of provision established for S1 and S2, which we refer to here as the Inter-disciplinary Programme.

This new programme was established as a pilot for CfE. It is notable for the clarity and coherence of its aims and organising themes (e.g. sustainable development; numeracy) and its clearly articulated links between methods (e.g. cooperative learning) and purposes. Nevertheless, it is evident that the programme remains somewhat limited in both its scope and impact, serving only junior pupils in the first two years of secondary school, and being detached from the rest of the subject-based curriculum. There are also questions raised in our research about the effectiveness of its implementation, particularly in respect of how it has engaged the whole staff, and in terms of communication. It is clear from our data that the programme has engaged some teachers very thoroughly, but that others felt excluded from the process.

Other, related initiatives in the school include an externally accredited award, which introduced an outdoor learning component. All teachers were trained in cooperative learning in 2008, and the school has made extensive use of local authority resources for formative assessment. As in Townview, a major focus under the current Head has been the development of staff collegiality. There is a fully developed programme of peer observation, and teachers are encouraged to share ideas at in-service training. There has been an emphasis on challenging existing practices through drawing on ideas from outside the school. One key member of staff was heavily involved leading a subject network, and several of the teachers most closely involved in the Inter-disciplinary Programme have undertaken Chartered Teacher programmes, involving university study at postgraduate level and action research in their own classrooms. A member of staff visited a school in Denmark, and his input about his observations was highly influential in the subsequent development of the Inter-disciplinary Programme. The Headteacher has to some extent encouraged distributed leadership through the school, for example initially giving two teachers collaborative responsibility for developing the Inter-disciplinary Programme (later involving input from a larger number of teachers from across the school). Moreover, the Headteacher was active in developing a clear vision for CfE and the methods by which it might be enacted. At times this was interpreted by staff as being over-directive, but it is clear that this vision has provided the impetus for many of the developments that have since occurred in the school.

The most recent inspection report stated that the then new Headteacher "had set out a clear strategic vision and had improved systems for communication with staff'. These features were less evident or (in the case of peer observation) more recently developed at Townview High School. 


\section{Teacher perspectives on developing Curriculum for Excellence}

\section{Townview High School}

Teacher attitudes towards CfE in our sample varied considerably. The ideas and philosophy behind CfE were warmly received by most interviewees, and were said to tie in with their own personal ideas about education. The Headteacher described the Four Capacities as 'a strong hook'; one teacher described them as 'exceptionally important', while another saw them as 'a brilliant idea'. A teacher focused on the constant need for refreshment within teaching, and within her department. She said she was very open to new ideas and new ways of working, and as such, she welcomed CfE, in that it encourages teachers to think about and change their practice. She felt teaching would become stagnant without this.

I think that's good, I think there needs to be a refresh; there are a lot of teachers who have been [here] 30 plus years. [...] You can get stagnant, if you don't change it up, freshen it up. [...] So bringing in and allowing staff to focus on new... maybe just refreshing the way they provide their learning and teaching, is good. (Teacher, Townview)

One teacher indicated she was initially very excited about CfE, saying that it 'fitted perfectly' with her view that education should look at the child holistically:

If you think about it beyond the politics, [the] capacities are brilliant. Seeing the kid as a whole and not just as you teaching knowledge in your own subject, it's a brilliant idea'. (Teacher, Townview)

Another held more negative views towards the new curriculum, describing it as 'change for change's sake'. A term used throughout both her interviews was 'if it ain't broke, don't fix it', and it was clear that she saw the former curriculum as being fit for purpose and without need of change. She described both CfE and the new qualifications framework as 'reinventing the wheel', and said teachers were 'floundering', trying to get their heads round the changes. She said that teachers were 'blind-folded', especially in terms of assessment, as they are unsure about the ultimate destination. ${ }^{4}$ This was a theme raised by teachers in the majority of schools (both secondary and primary), in which we conducted this research, including those in Braebank (Minty and Priestley 2012).

Although three of the four interviewees broadly welcomed CfE in principle, there was considerably less enthusiasm for it in practice. Again, this is a theme that was more evident across the wider dataset (Minty and Priestley 2012). Policymakers were criticised for failing to recognise the complexities involved in its implementation. The three teachers held extremely negative views towards national guidance for implementation and the structure of the curriculum. CfE was seen by two teachers to represent an existential threat to their school subjects, and they held substantial misconceptions about the curriculum. All Townhead interviewees were confused in terms of what was expected of them in relation to the new curriculum, although they did report having a greater sense of clarity by the time of the second interview. 
A particular issue involved what was seen as an existential threat to the specialist subjects taught by these teachers. One teacher's understanding of the new curriculum was centred around the idea that it meant the 'grouping together' of subjects, and building relations between them. Whilst she enjoyed the breadth of subject matter that she was able to bring to the inter-disciplinary courses she developed for $\mathrm{S}^{5}$, her focus throughout both interviews was upon preparing students to pass exams for which, she repeatedly said, you 'still need to have your experts'. Such anxieties were mirrored in her views on new, flatter management structures in the school, with faculties replacing discrete subject departments; 'faculties don't work. You have got to have an expert in the department'.

A second teacher raised similar concerns about the threat to her subject posed by CfE, which encourages teachers to teach outside of their disciplines, and likewise emphasised the importance of the role of the expert.

Okay fine, put a car out there, put a pupil into that car. Guaranteed they'd probably be able to zoom around in the car park doing something. They may be confident getting behind the wheel, 'well I'll do it, yeah no problem'. Are they competent? Are they effective? No. Very few people will go into a field without sufficient training from educated professionals and do things correctly. (Teacher, Townview)

This interviewee suggested that these attitudes were more widely prevalent across the whole staff at Townview.

It's in the staff. It's written all over their faces. People standing up and blatantly refusing to take part. 'This won't work, I won't do this'. And that's another problem. It's creating a divide in the staff. (Teacher, Townview)

Such perceptions partly lie in what was seen as the complexity of the new curriculum itself, and in a lack of clarity in its specification. A teacher who was broadly supportive of CfE in principle, described implementing it as a 'struggle'.

The practice of it is another story. I just think it is a huge amount of work to ask of teachers ... It's like someone asking you to do something but they are not quite sure what they want you to do. Therefore you have to define what they want you to do. (Teacher, Townview)

She referred to a new reporting system as an example. Teachers are encouraged to use the terms 'developing', 'consolidating' and 'secure' when assessing pupils' progress'. She and her departmental colleagues had developed a joint understanding as to how to use the terms in their reports. However, such discussions were not held in all departments, and as such the whole school reverted to the old system of reporting. She described this as a 'backward' step, given that pupils had been trained in using a three colour system in their self-assessments. She said it 'needs to be made easier to deliver in practice', and blamed the difficulties on bureaucracy, and the vagueness of what teachers were being asked to do; 'it's too abstract, it's not clear cut enough' and 'wishy washy', she said. She suggested teachers should be given more time to bring in the changes, that they should be given more structure in the curriculum, and that the government should consult with teachers 
more. Despite this, she pointed to the benefits of encouraging teachers to reflect on their own practice, which she said would not have happened without CfE. Whilst there were some aspects of CfE which she felt were already being done by teachers, it had justified some of her beliefs and 'probably clarified certain things'.

The CfE materials were considered to contribute to the lack of clarity around the new curriculum. The Head and the three teachers spoke of being overwhelmed by the amount of information ${ }^{7}$ contained within the curriculum folders, as explained by this teacher:

I feel more comfortable [since the first interview] but it's like when something gets handed to you at first - this big folder - you are like [draws in breath], learning outcomes. And then when actually you go into it - nobody has a clue! (Teacher, Townview)

This confusion was seen to emanate with external agencies, such as the government, the local authority and school inspectors. At a local level, this was linked to the current situation in respect of budget cuts and possible redundancies. However, teachers also pointed to barriers created in the local authority brought on by a lack of structure at a strategic level, and a proliferation of initiatives. A teacher summed the situation up thus:

Since I have arrived there has [sic] been huge changes. We had a temporary Headteacher .... basically pulling the school out the doldrums. We had, obviously, implementation of Curriculum for Excellence; we had the [local authority] policies coming out left, right and centre; HMIE. It's been a lot of change, a lot of admin and it is hard to put the brakes on and say 'I just want to get back to doing my job now'. (Teacher, Townview)

Whilst local authority working groups (including subject teacher networks) were seen as a strong driver in many respects, there was a perception that there were too many groups, and that there was often duplication or overlap between them; this was an issue also raised in Braebank. A Townview teacher described the 'piecemeal' approach as something which further added to disengage staff from the process of implementation.

There is no umbrella. [...] no central point to refer that to. So all these groups are doing great work, but not matching things up. [...] You can have three groups working on all these areas to develop a strategy for all three, and come out with three completely different documents. [There is] no council wide structure which concerns me quite greatly [...]. Staff become discontented. (Teacher, Townview)

\section{Braebank Academy}

It is interesting to note the strong similarities between the attitudes towards CfE expressed by teachers at Braebank and Townview, despite the differences between the two schools. In principle, most Braebank interviewees also welcomed the advent of a curriculum that advocates a reprofessionalising of teachers' work, and encourages students to become more autonomous in their learning. One teacher explicitly stated that she liked the soft skills and the emphasis on cooperative learning. Another commented on the desirability of making links between subjects, and saw CfE as 
an opportunity to make such links.

Before, education has always been 'this set of facts before this exam' and then you move on to the next stage. And quite often it doesn't flow from one stage to the next particularly. Whereas Curriculum for Excellence is looking for the continuity, you've got the skills there. [...] And then it can become much more subject focused. Cause I do like that idea, more collaboration between departments. (Teacher, Braebank)

However, as in Townview, concerns were expressed about the new curriculum. In common with their colleagues in Townview, teacher interviewees pointed to the vagueness of curriculum guidance; what one teacher referred to as the 'astonishing lack of clarity'. She called for the 'provision of resources that are effective and useful, while her colleague complained that 'we have lots of shiny documents and I'm afraid they don't mean a great deal'. This was attributed to a lack of communication between external agencies.

Similar to their colleagues at Townview, Braebank teachers also expressed concerns about the lack of strategic direction from the Scottish Government and the local authority.

It's astonishing, the lack of uniformity, [...] that you've got umpteen different schools using umpteen different projects. [....] Why are we producing sixteen different ways of doing this? One will do it. [...] That is just bad planning or poor planning. The Scottish Government or the local [authority] need to take responsibility. The structure needs to be centralised. (Teacher, Braebank)

Again echoing the views of Townview teachers, Braebank interviewees also expressed concerns about potential threats to their subjects, and the prioritising of skills over knowledge. This linked to the perceived repositioning of skills within $\mathrm{CfE}$, but was also partly a result of subject time being reduced and replaced by the Inter-disciplinary Programme lessons.

Some of the youngsters are the winners in the system. But some of them are equally losers. Because the school time for this [Inter-disciplinary] project had to come from somewhere. (Teacher, Braebank)

Likewise, Braebank interviewees expressed concerns about a proliferation in workload, and the complexity of working with multiple change initiatives. One teacher, while welcoming the autonomy inherent in CfE, felt that this would be undermined by increased paperwork.

\section{Approaches to innovation}

\section{Townview High School}

A common theme in this school is related to the point made earlier in the paper that CfE has created multiple, competing starting points for SBCD. In Townview High School, an audit approach to SBCD was clearly evident. SBCD was seen largely by our interviewees in terms of the tweaking of content to meet the demands of the curriculum outcomes - the Experiences and Outcomes of CfE. A teacher 
said that she conducted an audit, matching up 'every single learning outcome to what I did. [...] So I ticked all that'. Her colleague, comparing it to a 'jigsaw puzzle', said she did the same, checking off the outcomes that were already covered, and seeing 'what's left over'. This approach to SBCD can be viewed as strategic compliance, rather than a thorough and rigorous engagement with the new curriculum. The following extract shows how teachers 'tweaked' content to make it suit CfE.

I can cover all of these assessment parts in one, with one project here, one short project. It's not exactly the way they are saying it but you are not saying we can't do it this way. And it meets all the criteria. I can tick all the boxes quite confidently. And with the S1 stuff that I'm doing as well, that is one thing that you can see with Curriculum for Excellence that the rules aren't quite as strict [so] you can tweak them without feeling too guilty. (Teacher, Townview)

It was evident that this approach to SBCD was also associated with a perception that the enactment of CfE was an incremental matter, and that it was adding to workload and complexity in teachers' work. In the eyes of our interviewees, CfE was seen as something additional to implement on top of the already established core business of the school, rather than as a holistic framework within which coherent educational practice might be developed. Many aspects of CfE were thus seen to be in tension with existing practices. In particular, the emphasis on inter-disciplinary approaches jarred with pre-existing notions of essentialist bodies of knowledge encapsulated in subjects, foundationalist views of knowledge and transmission pedagogies. Associated with this were issues of risk. In a context where teachers' work is largely judged by success rates in examination passes, such change represented a considerable threat. The audit approach overtly sought to maintain the status quo within CfE where possible.

\section{Braebank Academy}

While teacher attitudes towards CfE appeared to be fairly similar in the two schools, there were significant differences in terms of the approaches to SBCD. In contrast to Townhead, where the audit of outcomes followed by incremental change was the predominant approach, at Braebank SBCD was driven far more by 'big ideas'. Audit of outcomes was still utilised, but at a far later stage in the process. It is clear that the Inter-disciplinary Programme has been primarily driven by a vision, clearly articulated by the Headteacher and (to a lesser extent) other key staff, of what education should be about. Interviews with the Headteacher and other key staff at Braebank indicated a strong willingness to engage; however, the data generally suggest that practice in this respect (in relation to the Inter-disciplinary Programme) was limited primarily to a smaller number of teachers who were directly involved with the programme.

The Headteacher's vision corresponds in many ways to the big ideas of CfE and the local authority's Learning, Teaching and Assessment policy. These include notions of inter-disciplinary learning (the making of cross-curricular links), the development of meta-cognitive capacity and other skills, and the use of cooperative learning methodologies to enable dialogic learning. However, the extent to which these policies were the stimulus for change was unclear. Indeed several teachers admitted to 
being ignorant of the Four Capacities of CfE and key local authority policy documents. What seems more likely from the interviews is that there has been a fortuitous conjunction of circumstances the appointment of a new Head with a clear strategic view; the stimulus provided by a negative inspection report; the permissions for innovation provided by national and council policy; the cognitive resources provided by training in methodologies such as cooperative learning; and teachers who were interested in new ways of working. This conjunction created a context that was clearly fertile for innovation, as the following two teachers explain:

But to the school's credit, it's very big in co-op learning and AifL. So that's the norm throughout this school in that sense. [...] And what I've seen, certainly since I've joined the school, it's a sea change from transmission teaching, one teacher talking. (Teacher, Braebank)

People are keen to try and develop. There's been a huge staffing shift in the school over the last four or five years, where there's a lot of staff who have been here for a long, long time. And you can understand why. It's a naturally very beautiful environment and it's a very comfortable school. The kids are great. And there's been a lot of new blood come in. And that allows the opportunity for [the Headteacher] to direct and look to pull different skill sets on people. Because they are made aware before they start that these are going to be expectations. As opposed to imposing something that is where you're fighting the resistance to change and you're not having the management of change process. (Teacher, Braebank)

While the philosophy and rationale behind the Inter-disciplinary Programme appear to be sound, the implementation process paints a more mixed picture. In particular, while there was considerable enthusiasm amongst some teachers for the approach, others were uneasy about the implementation of the programme. Some interviewees expressed concern that the inter-disciplinary project had become an extension of other subjects and that it was not a truly cross-curricular project.

There aren't any links across departments! There aren't any! ... [the Inter-disciplinary Programme] has just become another subject on the timetable and I don't think it's seen by staff as being an interdisciplinary course. (Teacher, Braebank)

As a teacher explained, this was partly due to the fact that anything which is timetabled ultimately becomes a subject. A number of teachers pointed to the compartmentalised structure of the Scottish secondary school as being a barrier to the Inter-disciplinary Programme, and to CfE more broadly.

This separate subject approach to the programme has contributed to a perceived separation between those teachers who are involved, and those who are not. We encountered resentment from some interviewees in relation to workload, the methods of selecting and recruiting teachers to the programme, and the consequent perceived reluctance and lack of engagement by some (echoing some of the issues raised in Townview with regard to $\mathrm{CfE}$ ). Involvement in the Inter-disciplinary Programme was not always voluntary, despite the apparent autonomy given to teachers once they were involved. Time (or lack of) and workload were clearly major issues in the implementation of the Inter-disciplinary Programme. While the school had partially addressed the need for time to enable 
teachers to make sense of the programme, it is clear that this was not always sufficiently available, particularly in terms of arranging inter-disciplinary meetings. A teacher noted the necessity of 'working lunches', and the difficulties engendered by reliance on these.

These issues detracted from the evident advantages of taking a 'big picture' approach to SBCD. Interviewees involved in the Inter-disciplinary Programme identified the benefits for their own teaching, and it is clear that the programme, once established, had subsequently influenced other parts of the curriculum. For example, some interviewees said that they were more readily able to transfer their approaches from the Inter-disciplinary Programme to their normal lessons. This included moving beyond their comfort zones into unfamiliar subject content.

But we're all learning an awful lot from it. I didn't do these subjects at school, but these are the most obvious things that link into this. And so for me it's a big learning curve. And a really enjoyable one. But at the beginning it was terrifying. But as long as the kids are aware that you're learning as well, that has helped. (Teacher, Braebank)

According to the Headteacher, people had become much happier to be observed and less insular in their practice than formerly. One teacher identified changes to teacher attitude and examples of previously unengaged teachers experimenting with new methods of working. She said that when talking to pupils, she could see that the 'metacognitive things that they are doing is [sic] finally coming through', and that they had become much better at working in groups and listening. While there were reported issues with the inter-disciplinary programme, there has clearly been an autocatalytic process that has fed innovation, leading to changes in practices within the school, and arguably raising the capacity of teachers to engage with SBCD.

But so what we've done is we've now taken those kind of ideas, we've put them into [the Interdisciplinary Programme]. So if it's been developed it can actually be done in this sort of stand-alone space. It's almost like a sort of a sandbox, a sandpit where we can experiment with different ideas. And they can go back out into the curriculum. So a lot of the co-operative learning work has started here and then moved out. (Teacher, Braebank)

\section{Discussion}

While the small scale of the research precludes generalisation, there are a number of conclusions that may be drawn from these findings. The similarities between the schools are striking. Both schools were subject to negative inspections, and changes in leadership. In both schools, there was considerable hostility from many teachers towards both national and local authority policy. And yet there are differences in terms of the schools' approaches to SBCD. Braebank Academy has innovated as a response to the problems faced, and had developed distinctive programmes to meet the challenges posed by changes in curriculum policy. It is fair to make this general claim, despite the implementation problems described in this paper. There is some evidence that Townview High School is also innovating, but with less apparent clarity of purpose at present. Whilst we recognise 
that Braebank is two years ahead of Townview in terms of the cycle of innovation, our research suggests that Braebank has responded proactively to $\mathrm{CfE}$, whereas Townview has until recently tended to react, often belatedly, in the face of policy. This is perhaps inevitable, given that the new Headteacher described the start of her headship as 'fire fighting' - trying to improve the reputation of the school first and deal with morale, before then being able to move onto the bigger picture. Nevertheless, at Braebank there is a clearer sense of purpose underpinning innovation, whereas at Townview innovation seems to be more piecemeal and fragmented, with some confusion about the big picture, and how the various parts fit together. Two questions arise prominently for us from this research.

The first is: why does one school innovate in the face of adversity, when a second school facing similar adversity fails to do so? The research suggests that in the case of these two schools, at least part of the answer lies in the existence or otherwise of a number of factors. Some of these are primarily cultural. Innovation requires changes to culture, otherwise new practices will inevitably be shaped by older, existing institutional logics, rather than by the intrinsic logics of the innovation policy (Young 1998). CfE represents a new and different set of cultural forms (Archer, 1988), contrasting with existing cultural forms within secondary schools. According to Archer, the most likely outcome, when existing cultural forms are challenged by new ideologies, is a process of hybridisation, as new ideas are assimilated into existing cultures. The degree to which the new ideas supplant the old is likely to be dependent on the extent to which they are understood and acted upon by key actors, in this case teachers. Archer's social theory provides a useful lens with which to view the implementation of a new curriculum. We suggest that innovation has occurred in Braebank Academy in because there is a clear, holistic vision of the big ideas of the new curriculum, and a clear appreciation of the methods needed to put them into practice. Thus, for example, teachers were able to see how cooperative learning and inter-disciplinary approaches were tools for achieving curricular purposes. This vision therefore provides a set of cultural resources upon which practitioners can draw in framing innovation; a clear cultural alternative to existing modes of practice. Conversely in Townview High School, this holistic vision was, at the time of the research, manifestly absent, with a lack of clarity about the new curriculum, and staff struggling to articulate how various local authority-led pedagogic initiatives linked to the big ideas of the curriculum. Innovation thus tended to be framed around existing solutions, and existing practices, rather than through the formulation of cultural alternatives.

Other contributory factors are structural. Innovation at Braebank was broadly facilitated by the development/existence of social structures in the school that were propitious to the realisation of cultural alternatives to existing practice. These included the roles of the Headteacher, who actively utilised her positioning to promulgate change, and distributed leaders, whom were granted considerable autonomy to develop the Headteacher's vision. Collegial relationships - for example those developed through the school's peer observations systems - clearly helped to stimulate innovation activity, albeit with the caveats noted in the above discussion of the school. The existence 
of strong external ties (Coburn and Russell 2008) further enhanced some teachers' ability to draw upon a wide repertoire for manoeuvre in their responses to national policy. Such horizontal, reciprocal and substantive working relationships appear to have enhanced the agency of the teachers as they enact new and often unfamiliar policy (see Priestley, Biesta and Robinson 2012, for a fuller discussion of the dynamic interplay of culture and structure in school settings). As we indicated, these factors are less developed at Townview, providing a likely explanation for the lack of substantive innovation to date in response to CfE (although we note embryonic signs of their development, suggesting that it will be interesting see how the school progresses over the next couple of years).

A second question relates to national and council policy: how might curriculum policy raise capacity for $S B C D$ ? In common with other countries, Scotland has framed its curriculum in terms of outcomes to be achieved. Moreover, recent policy focusing on teachers as agents of change follows two decades of prescriptive curriculum policy that has arguably reduced capacity for SBCD in schools (see Priestley, Robinson and Biesta 2012). Our research suggests, indeed, that the enactment of CfE is largely dependent upon the capacity to develop the curriculum at a school level, and that this is often limited. Part of the issue lies in the lack of clarity in the big ideas of the curriculum. If CfE is to become a clear cultural alternative to existing curricular beliefs and practices, then policy and guidance should be framed clearly to facilitate practitioners' understandings of its key principles and purposes, and the methods by which it might be enacted. A further issue lies in guidance on process. This, particularly processes for SBCD, is far from evident in the morass of material emanating from the Scottish Government, its agencies and the local authorities. We suggest that such processes are essential if teachers are to make sense of complex, new curriculum policy, and translate this into meaningful practice. Future curriculum policy thus needs to explicitly develop and articulate clear processes for engagement, as part of a strategy to renew capacity for SBCD. It is intriguing that in Braebank, where the school was able to develop such processes (albeit incomplete and imperfect), there has been some success in innovating in response to CfE. We suggest that further research and development work is required to both empirically test this notion, and to further develop such processes, thus informing future policy.

\section{Acknowledgements}

We wish to thank the teachers who gave up their valuable time to take part in the project that included this research, and the Scottish Government for funding the project. We also wish to acknowledge the helpful feedback contributed by two anonymous reviewers.

\section{References}

Archer, M. 1988. Culture and Agency: the place of culture in social theory, Cambridge: Cambridge University Press.

Black, P., Harrison, C., Lee, C., Marshall, B. and Wiliam, D. 2002. Working inside the black box: assessment for learning in the classroom. London: King's College. 
Baumfield, V., Hulme, M., Livingston, K. and Menter, I. 2010. Consultation and engagement? The reshaping of teacher professionalism through curriculum reform in 21st Century Scotland, Scottish Educational Review, 42(2): 57-73.

Charmaz, K. 2000. "Grounded Theory: objectivist and constructivist methods". Handbook of Qualitative Research, Edited by Denzin, N.K. and Lincoln, Y. 109-126. London: Sage Publications.

Coburn, C.E. and Russell, J.L. 2008. District policy and teachers' social networks. Educational Evaluation and Policy Analysis, 30(3): 203-235.

Corbin, J. and Holt, N.J. 2005. "Grounded Theory". In Research Methods in the Social Sciences, Edited by B. Somekh, B. and Lewin, C. 49-55. London: Sage.

Cowie, M., Taylor, D. and Croxford, L. 2007. 'Tough, Intelligent Accountability' in Scottish Secondary Schools and the role of Standard Tables and Charts (STACS): A Critical Appraisal. Scottish Educational Review, 39(1): 29-50.

Cuban, L. 1988). Constancy and change in schools (1880s to the present). In P.W. Jackson (Ed.), Contributing to Educational Change: perspectives on policy and practice (pp. 85-105). Berkeley: McCutchan).

Cuban, L. 1998. How schools change reforms: Redefining reform success and failure. Teachers College Record, 99(3), 453-477.

Elmore, R. F. 2004. School Reform from the Inside Out: Policy, Practice, Performance, Cambridge, MA: Harvard Education Press.

Goodson, I.F. 2003. Professional knowledge, professional lives, Maidenhead: Open University Press.

Hayward, L. and Boyd, B. 2009. Building Teacher Learning Communities, Dingwall: The Highland Council.

Hayward, L., Priestley, M. and Young, M. 2004. Ruffling the calm of the ocean floor: Merging practice, policy and research in assessment in Scotland. Oxford Review of Education, 30(3): 397-415.

Hutchinson, C. and Hayward, L. 2005. The journey so far: assessment for learning in Scotland. The Curriculum Journal, 16(2): 225-248.

Keddie, A., Mills, M. and Pendergast, D. 2011. Fabricating and identity in neo-liberal times: performing schooling as 'number one'. Oxford Review of Education, 37(1): 75-92.

Kelly, A.V. 1999. The curriculum: Theory and practice, $4^{\text {th }}$ Edition, London: Paul Chapman Publishing.

Minty, S. and Priestley, M. 2012. Developing Curriculum for Excellence in Highland Schools: A report on the qualitative findings for the Highland Council and the Scottish Government. Stirling: University of Stirling.

Nieveen, N. 2011. Teachers' professional development in curriculum design in the Netherlands. Paper presented at the European Conference for Educational Research, Berlin, 14 September, 2011.

Osborn, M., Croll, P., Broadfoot, P., Pollard, A., McNess, E. and Triggs, P. 1997. "Policy into practice and practice into policy: creative mediation in the primary classroom". In Teachers and the National Curriculum, Edited by In Helsby, G. and McCulloch, G. 52-65. London: Cassell.

Priestley, M. 2010. Curriculum for Excellence: transformational change or business as usual? Scottish Educational Review, 42(1): 22-35.

Priestley, M. 2011a. Schools, teachers and curriculum change: a balancing act? Journal of Educational Change, 12(1): 1-23

Priestley, M. 2011b. Whatever happened to curriculum theory? Critical realism and curriculum change. Pedagogy, Culture and Society, 19(2): 221-237.

Priestley, M., Biesta, G.J.J. and Robinson, S. 2012. Understanding teacher agency: The importance of relationships. Paper presented at the Annual Meeting of the American Educational Research Association, Vancouver, Canada, 13-17 April 2012.

Priestley, M., Edwards, R., Miller, K. and Priestley, A. 2012. Teacher agency in curriculum making: agents of change and spaces for manoeuvre, Curriculum Inquiry, 43(2): 191-214

Priestley, M. and Humes, W. 2010. The Development of Scotland's Curriculum for Excellence: amnesia and déjà vu. Oxford Review of Education, 36(3): 345-361.

Priestley, M. and Miller, K. 2012. Educational change in Scotland: Policy, context and biography. The Curriculum Journal, 29(1): 99-116.

Priestley, M. and Minty, S. 2012a. Developing Curriculum for Excellence: Summary of findings from research in a Scottish local authority, Stirling: University of Stirling.

Priestley, M. and Minty, S. 2012b. Curriculum for Excellence: 'A brilliant idea, but..'. A paper presented at the European Conference for Educational Research, 21 September 2012, Cadiz.

Priestley, M., Biesta, G.J.J. \& Robinson, S. 2012. Understanding teacher agency: The importance of relationships. A paper presented at the Annual Meeting of the American Educational Research Association, Vancouver, Canada, 13-17 April 2012. 
Priestley, M., Robinson, S. and Biesta, G.J.J. 2012. "Teacher agency, performativity and curriculum change: Reinventing the teacher in the Scottish Curriculum for Excellence?" In Performativity across UK education: ethnographic cases of its effects, agency and reconstructions, Edited by Jeffrey, B. and Troman, G. 87-108. Painswick: EandE Publishing.

Reeves, J. 2008. Between a rock and a hard place? Curriculum for Excellence and the quality initiative in Scottish schools. Scottish Educational Review, 40(2): 6-16.

Scottish Government 2008. Building the Curriculum 3: a framework for learning and teaching, Edinburgh: Scottish Government.

SEED 2004. A Curriculum for Excellence, Edinburgh: Scottish Executive.

SEED 2006. A Curriculum for Excellence: progress and proposals, Edinburgh: Scottish Executive.

Sinnema, C. and Aitken, G. In press "Trends in International Curriculum Developments". In Reinventing the curriculum: new trends in curriculum policy and practice, Edited by Priestley, M. and Biesta, G.J.J. London: Continuum.

Smyth, J. and Shacklock, G. 1998. Re-making teaching: ideology, policy and practice, London: Routledge. Stenhouse, L. 1975. An Introduction to Curriculum Research and Development, London: Heinemann.

Supovitz, J.A. 2008. Implementation as Iterative Refraction. . In The Implementation gap: understanding reform in high schools, Edited by Supovitz, J.A. and Weinbaum, E.H. 151-172. New York: Teachers College Press.

Supovitz, J.A. and Weinbaum, E.H. 2008. Reform Implementation Revisited. In The Implementation gap: understanding reform in high schools, Edited by Supovitz, J.A. and Weinbaum, E.H. 1-21. New York: Teachers College Press.

Young, M. 1998. The Curriculum of the Future: from the 'new sociology of education' to a critical theory of learning, London: Routledge.

Young, M. 2008. From Constructivism to Realism in the Sociology of the Curriculum. Review of Research in Education, 32: 1-28.

Young, M. 2009. Alternative Educational Futures for a Knowledge Society. Socialism and Education. http://socialismandeducation.wordpress.com/2009/12/06/alternative-educational-futures-for-aknowledge-society (accessed on January 1, 2010).

\footnotetext{
${ }^{1}$ AifL was a programme of related projects designed to developed an holistic approach to assessment in schools. It has become most closely associated with assessment for learning (see: Black et al. 2002) and the development of formative assessment techniques (widely termed AifL techniques in Scottish schools). These include the sharing of learning intentions and success criteria with students, traffic lighting (the use of red, amber and green cards to facilitate classroom dialogue) and questioning techniques.

${ }^{2}$ These are statements of what young people should become as the result of undergoing an education in Scottish schools. According to CfE students should become Successful Learners, Confident Individuals, Effective Contributors and Responsible Citizens. Each of these capacities is broken down into a set of attributes (see http://www.educationscotland.gov.uk/thecurriculum/whatiscurriculumforexcellence/thepurposeofthecurriculum/index.as $\underline{p}$ for further details). The notion of capacities has been further criticised (see Biesta 2008; Watson 2011).

${ }^{3}$ Further details are found at: http://www.educationscotland.gov.uk/thecurriculum/howisthecurriculumorganised/experiencesandoutcomes/index.asp

${ }^{4}$ Full specification of the new National 4 and 5 qualifications, which replace current Standard Grade exams in 2013/14, was not available at the time of the research, being published in April 2012.

${ }^{5}$ In Scottish secondary schools, year cohorts are designated as S1-S6.

${ }^{6}$ These terms have been widely adopted in schools to differentiate within the levels specified in the Es\&Os. This perhaps is indicative of a general perception that the Es\&Os are too vague and need to be more specific, such as was the case with the former 5-14 curriculum outcomes.

${ }^{7}$ There is an apparent paradox between complaints that there is too much information, and parallel calls for more guidance. In fact CfE cannot be accused of not providing information; however, the multitude of documents have been criticised for being vague, unclear and confusing. In 2011, such complaints resulted in the government writing shorter summaries of each of the very long Building the Curriculum publications (e.g. Scottish Government, 2008).
} 